\title{
TELEVISION, CRECIMIENTO y CAMBIO SOCIAL
}

\author{
Javier Esteinou Madrid \\ Departamento de Educación y Comunicación de la Universidad Autónoma \\ Metropolitana, Unidad Xochimilco
}

\section{CULTURA Y CRECIMIENTO.}

Reflexionando sobre la relación que existe entre comunicación y desarrollo, podemos decir que crecimiento entendido como el mejoramiento general de los niveles de vida de la población a través de la satisfacción de sus necesidades básicas, ${ }^{1}$ es producto de un conjunto de factores y procesos sociales complejos, dentro de los cuales, el detonador de todos esos elementos es la adquisición de conciencia sobre las realidades que se tienen que promover. Esto significa que para que se produzca un desarrollo material de la sociedad antes se requiere generar un previo crecimiento mental de la misma. De lo contrario, no existen condiciones apropiadas para la gestación del desarrollo: el desenvolvimiento de un país, parte de la evolución de su intelecto y no de la multiplicación de simples acciones materiales.

Por ello, pensamos que la revolución más radical de una sociedad se da a partir del momento en que los individuos que la conforman modifican su concepción del hombre, del mundo y de la vida y la llevan a la práctica. La evolución de una nación empieza con su cambio cerebral y no con la simple mutación material.

A su vez, el progreso del pensamiento parte del conocimiento que nuestros sentidos adquieren de la realidad, y esto depende del grado de información veraz y oportuna que se recibe de ésta. De aquí, la importancia vertebral que ocupa actualmente el papel de la producción, difusión, almacenamiento y procesamiento de la información para la superación de los conflictos de nuestra sociedad.

1 Concepto definido a partir de las ideas expuestas para el trabajo de grupo del proyecto denominado Preparación básica de la formación de recursos humanos en comunicación para el desarrollo, Segunda Reunión de Consulta, UNESCO UIA, 1820 de mayo de 1987, México D.F. p. 1, Coordinador general del proyecto Mtro. Pablo Casares A. 
Tenemos que recordar que la distribución de información y de cargas emotivas de nuestra sociedad es un insumo central que acelera o retarda nuestro crecimiento colectivo: a mayor difusión, organicidad y objetividad en la circulación de la comunicación, mayor crecimiento de nuestra conciencia nacional y, por lo tanto, avance de la República. No debemos olvidar que la distribución de nueva información en el país, produce nuevas formas de conciencia, que a su vez, generan frescos cambios conductuales que transforman la nación.

Hay que tener presente que la televisión es una gran excitadora de nuestro cerebro y emotividad, y por lo tanto, de nuestra conciencia. Por ello, la difusión sistemática de realidades y afectividades sobre nuestros principales problemas nacionales a través de la televisión pública, puede provocar un avance cualitativo en el proceso de desarrollo de nuestra sociedad.

Sin embargo, hay que tener presente que no es la simple cantidad de difusión de información la que propicia el desarrollo, como lo han señalado las tesis desarrollistas, sino la calidad y organicidad que guarda ésta con respecto a las prioridades de crecimiento que se requieren resolver. ${ }^{2}$

Por lo tanto, hay que crear y transmitir aquellas informaciones que permitan relacionar nuestra toma de conciencia con aquellos programas de acción concreta que tiene instrumentados el aparato de gobierno y la sociedad civil para crecer. De lo contrario, de muy poco servirá la generación de conciencia social sobre nuestra problemática nacional, a través de la televisión, si ésta no encuentra una canalización específica mediante los proyectos de trabajo de la sociedad y del Estado: la información puede obrar como abono del cambio social, sólo si se coloca en el campo cultural y social propicio para germinar.

De aquí, que para lograr el desarrollo de nuestro pais, más que produciry distribuir gigantescos torrentes indiscriminados de información masiva sobre nuestros sentidos que lo que ocasionan es el embrute-cimiento y la enajenación de los mismos, se debe elaborar una jerarquia de necesidades informativas acordes con las prioridades de crecimiento que encara nuestra sociedad en cada fase de evolución por la que ésta atraviesa. Esto significa, que las necesidades de comunicación para la expansión de la sociedad mexicana en los últimos 80 años han sido muy distintas, en el período post revolucionario; que en la fase de industrialización; que en la etapa del "desarrollo estabilizador"; que en el momento del "boom petrolero"; que en la actual época de dependencia alimentaria; que en la era de la destrucción ecológica; que en el tránsito de la 2 Para revisar como no es la cantidad de información que se arroja a la sociedad, vía las viejas y nuevas tecnologías de comunicación, lo que provoca el desarrollo social, consultar nuestro trabajo El sistema Morelos de satélites y su impacto en la sociedad mexicana, V Encuentro Latinoamericano de Facultades de Comunicación Social, Bogotá, Colombia, 6 al10 de octubre de 1986, página 29. 
nueva tercera revolución industrial que experimentamos; que en los tiempos de la más alta concentración urbana que sufrimos; que en la fase de transición democrática que hoy vivimos; que las que se tendrán que encarar para principios del siglo XXI, etc.

Es dentro de este contexto que la televisión, como el principal medio de comunicación colectiva de nuestra civilización, ocupa un papel central en el desarrollo de las mentalidades y sensibilidades, y por lo tanto, en el desarrollo del país: hoy día la televisión se ha convertido en el sistema nervioso fundamental del avance o retroceso de nuestra cotidiana cultura nacional. ${ }^{3}$

Por ello, aunque estamos conscientes que la televisión no produce efectos automáticos sobre el auditorio. Que no es una aguja hipodérmica que inyecta mecánicamente sus contenidos en los cambios de la población. Que existen múltiples formas de interpretar por parte del auditorio los mensajes televisivos que recibe. Que por parte de los emisores no existen efectos acabados sobre los auditorios como hemos creído en años anteriores. Que no es omnipotente para producir procesos mágicos. Que normalmente refuerza tendencias previamente ya existentes en el seno de las comunidades. Que la conciencia humana no solamente se produce por la acción simbólica de la televisión, sino por un conjunto más amplio de relaciones sociales y de redes culturales que impactan sobre la inteligencia y la sensibilidad de los individuos. Que su efectividad de convencimiento no depende totalmente de las imágenes que se transmiten sino de otros procesos sociales complementarios, etc. También sabemos que, a través de las propiedades físicas que ha conquistado y de los hábitos culturales que ha formado, la televisión cuenta con un alto margen de eficacia persuasiva comprobada para crear y cambiar las formas de pensar y actuar en México.

En la actualidad debemos tener presente que en nuestro país, frente a la tradicional acción del sistema escolar y religioso, la televisión se ha convertido en la principal red educativa capaz de cambiar, con mayor rapidez y agilidad, los valores, las actitudes, los hábitos y las conductas de los receptores. En una idea, dirige la cultura cotidiana en cada sexenio de gobierno. Es decir, la televisión se ha transformado en el principal mediador cultural, a través del cual el Estado articula ideológicamente a nuestra sociedad, convirtiéndose en la principal organizadora colectiva de la historia moderna de México.

3 Para comprender porqué la televisión se ha convertido en el principal medio de comunicación en la sociedad contemporánea, consultar nuestro trabajo: Los medios de comunicación y la construcción de la hegemonía, Editorial Nueva Imagen Centro de Estudios Económicos, Políticos y Sociales del Tercer Mundo (CEESTEM), México, D.F., 1983. 
Sin embargo, esta mediación central que ejerce la televisión entre gobierno y sociedad, no significa, en ningún momento, que la capacidad de persuasión que realiza sea omnipotentemente eficaz para convertir en socialmente dominante cualquier mensaje transmitido por ésta y mecánicamente doblegar las conciencias y las acciones de todos los ciudadanos que son tocados por ésta. La capacidad de convencimiento de la televisión tiene límites de competencia muy precisos, y los principales son los tres siguientes:

Primero, las informaciones televisivas que leen, decodifican e interiorizan los receptores nunca se asimilan homogéneamente en todos ellos con el mismo signo ideológico e intensidad personal con la que se emiten, sino que varían según son sus situaciones históricas, antropológicas, religiosas, económicas, familiares, políticas, culturales, materiales, regionales, étnicas, productivas, etc., que los determinan como seres humanos. No debemos olvidar que los públicos no son pasivos, ni neutros, ni socialmente vírgenes, sino que éstos practican sus propios procesamientos de lo que la televisión les ofrece de acuerdo a sus propias experiencias de vida y sus inserciones sociales. ${ }^{4}$

Segundo, la habilidad seductora de la televisión nunca puede rebasar el peso de la realidad que enfrentan los espectadores, pues siempre las circunstancias de sus vidas concretas son más fuertes que el poder que alcanza la información y las imágenes audiovisuales que se difunden. Es necesario subrayar que la televisión no sustituye a la dinámica económica, política y social, sino que la apoya o debilita con base en los proyectos globales que existen detrás de ésta. De lo contrario, sobrevaloraríamos el papel de la televisión al otorgarle fantasiosamente una absoluta propiedad transformadora, cuando en verdad sólo es una tecnología muy perfeccionada de promoción de intereses o políticas precisas.

Tercero, cuando la gama de discurso que transmite la televisión encuentra las condiciones psicológicas favorables en los campos de conciencia de los públicos, estos son asimilados en un alto porcentaje y viceversa.

4 Por otra parte, es alarmante y aleccionador para la sociología crítica del estudio del receptor, que quienes con mayor exactitud, sutileza y eficacia conocen el perfil de comportamiento del auditorio es el sector dominante, que impulsado básicamente por el capital industrial y comercial, se dedica, a través de las técnicas de la mercadotecnia y publicidad, a radiografiar los diversos patrones de aspiraciones, gustos, comportamientos, debilidades, actitudes, preferencias, inclinaciones, etc., del receptor, con objeto de integrarlo al proyecto de desarrollo del capital nacional e internacional. Javier Esteinou Madrid, El estudio materialista de la comunicación de masas, Cuadernos del TICOM No. 1, Taller de Investigación para la Comunicación Masiva, Departamento de Educación y Comunicación, Universidad Autónoma Metropolitana, Unidad Xochimilco, marzo de 1979, p.9. 
Es por estas razones, que al alterarse dichos límites, los contenidos de la omnipresente, redundante, ultra- moderna y amplísima imagen televisiva del Partido Revolucionario Institucional (PRI) y del candidato presidencial, Carlos Salinas de Gortari, no encontraron recepción en la inteligencia de la mayoría de los ciudadanos y los contenidos de la televisión oficial fueron derrotados de manera drástica en las últimas elecciones para Presidente, Diputados y Senadores el 6 de julio de 1988. Ello, provocado porque la campaña de venta de la imagen partidista que se montó violó las siguientes dos leyes básicas del funcionamiento de la propaganda política:

En primer término, se olvidó que el exceso de frecuencia de exposición visual de una propuesta partidista genera una acción totalmente contraria al fin buscado en la sensibilidad de la comunidad. En este sentido, al pensar el PRI que el uso desmedido de la repetición, a través de los medios públicos y privados, era el puente mágico para enlazar candidatos y masas con el fin de obtener el voto, olvidando que la aplicación del oficio político era la única vía para ganar la real voluntad popular, lo único que consiguió fue la indigestión política del auditorio ante cualquier sugerencia del partido tricolor (La relación de proporción de intensidad de presentación en la pantalla fue aproximadamente de 10 anuncios del PRI por uno de la oposición).

En segundo término, la propuesta de los contenidos emitidos estuvieron cargados de pronunciamientos y promesas poco creíbles, envueltos en lenguajes muy desgastados que fueron calificados mayoritariamente como demagógicos. En este sentido, los pobladores, especialmente de las grandes ciudades, mostraron que todavía tienen muchos elementos de su experiencia cotidiana y de su memoria para enfrentar al poder televisivo, no creerle, e incluso, actuar en su contra. ${ }^{5}$

De todo esto, aprendimos que la televisión, por sí sola, es incapaz de mover voluntades, cambiar ideologías, y sobre todo convencer algo totalmente opuesto a lo que el público vive de manera cotidiana. Tenemos que reconocer que la realidad es más fuerte que la presencia de todos los signos televisivos juntos, sobre- todo cuando éstos insisten en apartarse de la verdad, y en

5 Algunos otros ejemplos que nos permiten comprender el poder limitado de la televisión, lo encontramos cuando Juan Domingo Perón es elegido presidente de Argentina en 1946, cuando tuvo toda la "gran prensa" en su contra y con parte de ésta en 1973, y derrocado con toda la prensa a su favor en 1955. O también cuando en julio de 1979 el general Anastasio So moza es derrocado en Nicaragua por el Frente Sandinista de Liberación Nacional, no obstante controlar y dominar durante más de 30 años la estructura y dinámica vertical del aparato de la cultura nacional. Esteinou Madrid, Javier, Los medios de comunicación y la construcción de la hegemonía, Editorial Nueva Imagen, México D.F., 1983, p. 110. 
volverse retóricos, huecos y vacíos de contenido. Con ello, le quedó demostrado al poder que no es lo mismo vender detergentes que plataformas políticas. $^{6}$

Empero, no obstante la existencia de diversos límites reales en la tarea de mediación social que realiza la televisión entre pueblo y gobierno, su capacidad de persuasión y de movilización de la población en el país ha sido tan eficiente en diversos momentos, que ha generado fuertes fenómenos sociales de signos contrarios. Así, por ejemplo, en un sentido positivo constatamos cómo a través de las acciones promociónales de la televisión, se ha colaborado a reducir en la última década la tasa de crecimiento demográfico del $4.3 \%$ al $2 \%$ construyendo un nuevo modelo cultural de familia basado en cuatro miembros: padre, madre y dos hijos. De igual forma, se ha contribuido a alfabetizar y a otorgar instrucción básica a través de la te le secundaria a miles de mexicanos, a tal grado, que de 1983 a 1987 se redujo el índice de analfabetismo en sujetos mayores de 15 años del 14 al $7.1 \%$, alfabetizando a más de 3 millones 300 mil mexicanos. Esto significa que hay 92 de cada 100 mexicanos adultos que ya saben leer y escribir en el país. ${ }^{7}$

De la misma manera, ha logrado promover permanentemente la donación altruista de sangre a hospitales y bancos de plasma. ${ }^{8}$ Asimismo, con apoyo de las campañas de prevención médica vía televisión, la acciones del sector salud, la participación de 600 mil voluntarios y la instalación de $80 \mathrm{mil}$ puestos de vacunación, se pudo inmunizar en dos [mes de semana de 1987 en todo el territorio nacional a más de 12 millones de niños contra la poliomielitis, a 10 millones de pequeños contra la difteria y la tosferina, y a 2 millones de niños contra el sarampión, que en conjunto han alcanzado reducir en más del 35\% las enfermedades infantiles en la República. ${ }^{9}$

6 Víctor M. Bernal Sahagún, Programa Intersticios, tema: La publicidad, Radio Educación, 18 de julio de 1988; Florence Toussaint, La televisión y los resultados electorales, Proceso, 25 de julio de 1988, p. 58; Fracasó la televisión, no todo es vender detergentes, Excelsior, 5 de agosto de 1988.

7 Hoy 92 de cada 100 adultos mexicanos saben leer y escribir, Excelsior, 13 de diciembre de 1986; Reconocimiento de la UNESCO al gobierno mexicano por los resultados de programas de alfabetización, Uno Más Uno, 9 de septiembre de 1987; Descendió el analfabetismo a 7.6\%, Uno Más Uno, 27 de marzo de 1987.

8 Respuesta al festival del donador altruista de sangre, Excelsior, 14 de octubre de 1987.

9 Las campañas de vacunación han logrado reducir 35\% las enfermedades infantiles, Excelsior, 12 de marzo de 1986; El próximo sábado la segunda jornada de vacunación antipolio, Excelsior, 22 de marzo de 1986; Serán inmunizados contra la polio más de doce millones de niños, Excelsior, 14 de enero de 1987; Millón y medio de niños serán vacunados contra la 
También, por la acción instructiva de la televisión y otros medios de comunicación, se ha formado en los últimos dos sexenios una nueva cultura financiera de masas que ha logrado crear una base de educación económica que permite que la clase media y algunos sectores de la clase popular sepan cómo invertir sus ahorros en diversos instrumentos de capitalización, como son plazos bancarios a una semana, un mes, tres meses, seis meses, en renta variable, papel comercial, petrobonos, acciones de empresas, etc. En los mismos términos, en los spots televisivos transmitidos de 1984 a 1985 consiguieron abarrotar los Registros Civiles del país para regularizar las uniones libres de las parejas y registrar oficialmente a sus hijos. En idéntico sentido, la repetición publicitaria a través de la televisión ha creado en las ciudades desde hace 15 años a la fecha una cultura de uso de la toalla sanitaria que las mujeres urbanas, y se nota cada vez más con marcada claridad, que también ya empieza a surgir en el campo.

Igualmente, se logró que los ciudadanos hicieran valer más sus derechos como compradores mediante la educación televisiva que ha proporcionado el Instituto Nacional del Consumidor y la Procuraduría Federal del mismo en los últimos 12 años. ${ }^{10}$ De igual forma, se obtuvo que a través de la promoción televisiva más de 80 mil pedalistas participaran en 1987 en el Paseo Ciclista de la Constitución, 15 mil atletas asistieran a la Sexagésima Tercera Carrera de la Constitución en el D.F. y 4 mil deportistas estuvieran presentes en el IV Maratón Deportivo Guadalajara. ${ }^{11}$

También a partir de la difusión de la propaganda audiovisual sobre la prevención de los accidentes de trabajo y la capacitación de aproximadamente un millón de funcionarios públicos por el Instituto Mexicano del Seguro Social, se obtuvo que los percances de trabajo en las empresas se redujeran el año pasado en $57 .{ }^{12}$ En idéntico sentido a través del incremento de las

polio en el D.F., Excelsior, 21 de enero de 1987; Aplicarán hoya 12 millones de infantes la vacuna antipolio, Excelsior, 24 de enero de 1987; Se inmunizó contra la polio a 12 millones de infantes, Excelsior, 25 de enero de 1987; Aplicó la armada 75 mil dosis de vacuna antipolio, Excelsior, 29 de enero de 1987; Vacunados más de 10 millones de niños contra difteria y tosferina, Excelsior, 23 de mayo de 1987; Del 26 al 30, vacunas contra el sarampión: SSA, Uno más Uno, 20 de octubre de 1987.

10 Cada vez más consumidores hacen valer sus derechos: Pliego Montes, Excelsior, $11 \mathrm{de}$ febrero de 1987.

$11 \mathrm{Al}$ maratón de Guadalajara 4,000 corredores, Excelsior, 4 de febrero de 1987; 15,000 atletas en la carrera de la Constitución, Excelsior, 8 de febrero de 1987; El paseo ciclista, un freno a la contaminación, Excelsior, 5 de junio de 1987.

12 Bajaron los accidentes laborales en 57\%: IMSS, Excelsior, 10 de febrero de 1987. 
campañas publicitarias, en $80 \%$ en prensa, $110 \%$ en revistas, $85 \%$ en radio y $200 \%$ en televisión, la iniciativa privada pudo sostener la demanda de consumo de la población en ciertos renglones excepto el sector textil, la industria zapatera y la industria auto- motriz que fueron afectadas drásticamente por la crisis económica de $1987 .{ }^{13}$ Asimismo, mediante la promoción televisiva y la preparación de 450 mil promotores del voto por parte de la Federación de Trabajadores al Servicio del Estado se logró que el 85\% de los ciudadanos en edad de votar se registraran voluntariamente en el Padrón Electoral para participar en las elecciones presidenciales de $1988 .{ }^{14}$

Igualmente, otro caso sumamente meritorio de persuasión y movilización de la sociedad mexicana ocurrió ante los terremotos de 1985, donde a través de la televisión y otros medios de comunicación, el conjunto social se sensibilizó de la magnitud de la tragedia y logró vincular las urgentes demandas de socorro con los ofrecimientos de ayuda voluntaria de los ciudadanos, creando un movimiento de solidaridad civil que no se había presenciado en las últimas cinco décadas. ${ }^{15}$

Mediante otras acciones persuasivas la -televisión nos ha reeducado cotidianamente para sustituir en nuestro registro de domicilio la colonia por el código postal. Para agregar otra cifra cabezal por zonas cuan- do el número telefónico rebasó los seis dígitos. Para aceptar las nuevas instalaciones en nuestro hogar que permitieron el cambio de voltaje de 120 a 110 volts. Para cambiar las placas al nuevo sistema de referencia permanente. Para pagar los impuestos de las personas físicas y morales en las fechas indicadas, etc.

Por otro lado, en un sentido negativo presenciamos cómo la televisión ha propiciado a lo largo de los años un permanente ciclo consumista que provoca el desperdicio de gran parte de la energía de nuestra sociedad. A través de las imágenes que diariamente se difunden, constatamos cómo la televisión reconstruye en la pantalla otro país que no es México. De igual forma, mediante los valores televisivos que se proyectan, observamos como la televisión ha generado un fuerte corrimiento de la frontera ideológica nacional que ha propiciado la desmedida admiración por el estilo de vida y éxito norteamericanos y el rechazo a los netamente local, etcétera.

13 Reconoció MMH el apoyo publicitario a las campañas del sector público, Excelsior, 29 de septiembre de 1987.

14 Está preparando al FSTSE a 450,000 promotores del voto, Excelsior, 2 de julio de 1987.

15 Esteinou Madrid, Javier, La reconstrucción y los medios de comunicación, El Búho. No. 15, suplemento cultural de Excelsior, 22 de diciembre de 1985; Esteinou Madrid, Javier, Televisión y memoria social (dos partes), El Búho, Nos. 35 Y 36, Excelsior, 11 y 18 de mayo de 1986 
Por ello, nos preguntamos, si durante décadas la televisión ha sido capaz de provocar nuestro cambio mental y afectivo para optar por otro whisky, brandy, cigarros, perfumes, automóviles, valores, creencias, etc., ¿por qué no va a poder hacer cambiar nuestra mentalidad frente a los grandes problemas de desarrollo que enfrentamos como pais? Por lo mismo, es necesario analizar de qué manera las televisoras pueden colaborar a producir en sus auditorios una cultura de avance nacional y no de retroceso regional.

\section{II.- HACIA OTRO CAMBIO MENTAL VIA LOS MEDIOS DE CO- MUNICACION.}

A diferencia de la estrategia mercadológica o hollywodense que concibe a los receptores como meros consumidores reales o potenciales diferenciados por estratos de ingresos y que ha sido enormemente asimilada por los modelos mexicanos de televisión, nosotros pensamos que las televisoras de Estado deben comprender a sus auditorios como complejos sectores humanos enmarcados por múltiples problemáticas educativas, laborales, económicas, habitacionales, étnicas, nutricionales, lingüísticas, políticas, etc., que deben resolver para subsistir. Es decir, deben ser abordadas como sectores que se encuentran en distintas fases de su desarrollo económico, político, social y cultural, y no como meros receptores pasivos de información y decisiones centrales.

Por consiguiente, dentro de esta perspectiva, los medios audiovisuales deben funcionar frente a sus públicos como tecnologías culturales capaces de producir cargas informativas y atmósferas emotivas que puedan generar conciencia para enfrentar las contradicciones que impiden su progreso. En otras palabras, las televisoras deben actuar como instrumentos culturales de desarrollo nacional y regional, a través de la distribución de sensibilidades y conocimientos especializados por zonas de conflictos, y no como empresas aisladas productoras de abundante información parasitaria desvinculada de las urgentes necesidades municipales y estatales donde actúan. Situación que ha sido enormemente demandada por los diversos grupos sociales y políticos de la sociedad mexicana.

Esto implica que las televisoras de Estado como mediadoras culturales entre el gobierno y la sociedad, a través de la elaboración y la difusión de diversas subjetividades y sensibilidades sobre nuestros obstáculos de desarrollo, deben gestar un ágil y permanente proceso de transformación de las estructuras mentales de la población frente a los grandes problemas nacionales y regionales que les impiden crecer. Ello exige que las televisoras públicas, en conjunto con otros aparatos culturales, a través de su programación, formen 
otra neocorteza cerebral de conocimientos y sentimientos en el país que nos permita armonizar coherentemente nuestras acciones colectivas como sociedad, con las urgentes necesidades nacionales de crecimiento que hay que solucionar para prosperar. Creemos que hoy día el mayor problema del país no es el pago de la deuda externa, ni el alto desempleo, ni la aguda inflación, ni la avanzada contaminación, ni la agobiante carestía, ni la ausencia de vivienda, ni la urgente modernización, etc. "sino nuestra transformación mental y emotiva como sociedad frente a nuestros conflictos de crecimiento para poderlos resolver.

Esto requiere la creación de un nuevo proceso de educación cotidiana de nuestras inteligencias y sentimientos para adquirir a través de las televisoras, mayores márgenes de claridad y sensibilidad colectivas sobre nuestras demandas de desarrollo y sus respectivas salidas. Tenemos que pasar de aplicar un proyecto televisivo narcotizante y fugaz, que en el mejor de los casos informa sobre algunos hechos; a instrumentar un proyecto de televisión que nos sensibilice sobre nuestras necesidades de desarrollo y movilice a la sociedad en función a la solución de las mismas. Ello implica producir para cada momento de nuestro crecimiento una ecoconciencia que nos permita abrir nuestros horizontes de conocimientos y sentimientos individuales hacia una nueva macrovisión cósmica que amplíe nuestros límites de lo posible y nos permita regresar al ciclo vital de la vida y de la naturaleza del cual velozmente nos hemos alejado tanto.

Esta moderna acción de reeducación cotidiana, exige reducir la enorme distancia que actualmente existe entre la información y la afectividad que producen las televisoras públicas, con las necesidades de desarrollo que enfrenta nuestra sociedad para afianzarse como nación. La televisión de Estado tiene que convertirse en un instrumento que active el desarrollo de la sociedad y que no lo retarde: la televisión pública nos puede hacer dar pasos de avance infinitos en la ampliación de nuestra conciencia a ritmos más acelerados que los que se han logrado en décadas anteriores, para llegar a ser una sociedad superior y no una simple masa inferior de habitantes.

Por ello, hay que recapacitar que salvo los problemas que nos impone la dinámica de la naturaleza como son las inundaciones en el Bajío, los terremotos en el Valle de México, las heladas en la frontera norte, las plagas en el Golfo, las sequías en las zonas áridas, los huracanes en las costas, etc., el resto de los problemas que tenemos en nuestra sociedad, como la creciente pobreza, la fuerte desnutrición, las altas tasas de natalidad, la destrucción eco lógica, la arraigada corrupción, la macro concentración urbana, el aniquilamiento de especies animales, el uso irracional de recursos energéticos, el acentuado alcoholismo, el grave desempleo, la seria farmacodependencia, 
etc., son realidades producidas por la mente del hombre y que pueden modificarse en la medida que se corrijan nuestras estructuras cerebrales y afectivas como sociedad. Es decir, aunque aparentemente todas estas contradicciones surgen por procesos políticos, por formas de organización social, de tendencias históricas, de modelos de producción, de herencias materiales, de determinaciones económicas, de desequilibrios entre campo y ciudad, etc., en última instancia, todos estos hechos parten de las visiones profundas, que los individuos poseen sobre el hombre, el mundo y la vida.

Por lo mismo, frente a este panorama, es necesario subrayar que son situaciones que no nos imponen las fuerzas naturales, sino que las genera el entendimiento deformado de los mexicanos. Por ello, insistimos que en nuestro pais podrá existir progreso tecnológico, aumento de riqueza, expansión material, incremento de las comunicaciones, perfeccionamiento cientifico, reagrupación politica, modernización social, etc., pero si no hay transformación de nuestras estructuras psiquicas, finalmente, no hay avance de nuestra sociedad. De aquí la trascendental importancia de educar y modificar nuestras bases de inteligencia para crecer como país. Para esto, contamos en nuestra sociedad con el aparato educativo tecnológicamente más desarrollado y perfeccionado, hoy día, que es la televisión.

En la construcción de esta alternativa es importante tener presente que la clave para producir este nuevo proyecto de cultura nacional a través de la televisión, no consiste en sólo generar programas de nacionalidad mexicana y ya no importar contenidos, es decir, mexicanizar la pantalla, pues podemos producir todas las horas visuales que deseemos sin alcanzar avances en la formación de nuestra conciencia nacional. Lo que se requiere para crecer es elaborar una programación audiovisual que colabore a cambiar nuestras conductas colectivas sobre los grandes conflictos de desarrollo que encaramos.

Sabemos que la transformación mental y afectiva de nuestra sociedad no es tarea ni responsabilidad única de la televisión de Estado sino del conjunto complejo de medios de comunicación y de instituciones culturales que existen en el país. Por ello, será en la medida en que todos los canales de difusión accionen a corto, mediano y largo plazo en esta misma dirección, que podrán darse procesos de profunda modificación ideológico afectivo y de reorganización de la comunidad en función a sus urgencias inmediatas como se logró sorprendentemente ante los terremotos del 19 y 20 de septiembre de 1985.

Sin embargo, mientras despiertan y reaccionan el sistema global de medios de comunicación y de cultura en esta perspectiva, es necesario considerar que la televisión ocupa un papel central en la promoción de nuestra identidad y sensibilidad nacionales pues se ha convertido en el principal instrumento 
intelectual a través del cual cotidianamente la población reconstruye en su inteligencia la realidad macro social con la que se relaciona. De aquí la importancia de propiciar la transformación profunda de esta institución cerebral del país.

Por lo anterior, creemos que una televisión pública que no fomente en población un permanente proceso emotivo y racional que nos conduzca al análisis y a la autocrítica para regresar a nosotros mismos como personas, como familia, como barrio, como delegación, como municipio, como estado, como región, como cultura, como nación y como humanidad, es una televisión que no generará un avance en sus auditorios, pues propiciará que nuestra conciencia y afectividad se continúe evadiendo de la realidad concreta sin enfrentar los obstáculos que debemos asimilar para superarlos y crecer. Esto fomentará que la energía colectiva del país se continúe perdiendo a través de los ciclos ideológicos del desperdicio mental que erosionan salvajemente la formación de nuestra identidad nacional, y por consiguiente, prosiga el derroche de este monumental recurso psíquico de la sociedad para construir una nueva fase de la nación: nuestra energía mental.

Ante ello, nos cuestionamos, ¿De qué sirven los desarrollados ojos tecnológicos que ha construido la televisión si a través de éstos no podemos mirar a México, ni tampoco nuestro interior? El continuar conservando la opacidad de nuestra conciencia colectiva frente a nuestros fuertes conflictos de crecimiento, prolongará la confusión y el debilitamiento de la mar- cha de la sociedad, pues evitará la atención de su malestar interno impidiendo su progreso. Hay que considerar que los problemas de nuestra sociedad únicamente podrán ser resueltos en la medida en que colectivamente adquiramos conciencia racional y emotiva de su existencia y no en el porcentaje que los olvidemos. La televisión debe optar por la vida y no por la muerte del pais: si no forma conciencia sobre los conflictos nacionales, se inclina por la muerte de nuestra sociedad.

Pensamos que para desentrañar la relación entre el funcionamiento de las televisoras públicas y la satisfacción de los más relevantes problemas nacionales, y a su vez, para construir este proceso afectivo y racional en el interior de la República, debemos de partir de las respuestas a algunas de las siguientes preguntas: ¿Hoy día, qué información es la que deben generar las estaciones de televisión frente a los requerimientos de desarrollo que encaran sus públicos? ¿Qué mapas mentales hay que crear para las próximas décadas de la crisis nacional? ¿Qué actitudes colectivas hay que introducir en los ciudadanos para atenuar la caída vertical del país? ¿Qué valores hay que interiorizar para que los 
mexicanos nos sintamos seguros de ser mexicanos? ¿Qué sensibilidad hay que despertar para fortalecer la cohesión de nuestro Estado Nación? ¿Qué ciclos culturales hay que armar para rescatar la identidad regional?

¿Qué clase de información hay que distribuir en los hogares mexicanos para alcanzar un crecimiento sostenido de 3.5 al 4\% como pretende el gobierno mexicano? ¿Qué conductas grupales hay que despertar frente al surgimiento de la nueva revolución industrial, ahora denominada reconversión industrial que cambiará radicalmente la estructura de nuestra sociedad? ¿Qué tipo de realidades hay que difundir cuando el modelo de desarrollo que ha sostenido a la sociedad mexicana en los últimos 60 años ya se ha agotado y la era del petróleo ya vislumbra su fin? ¿Cómo construir, a través de la televisión, un Estado Nación más sólido que se pueda enfrentar al nuevo proyecto transnacional del capital financiero que presiona por debilitar a nuestro gobierno? ¿Qué clase de información hay que distribuir a las inteligencias del país para despetrolizar la economía mexicana y vivir lo más justamente esta etapa de transición energética y social por la que atravesamos?

¿Cómo convocar a través de la televisión a los principales sectores del país alrededor de un sólo proyecto de crecimiento que le dé una nueva fuerza histórica al Estado Mexicano? ¿Qué políticas culturales deben promover la televisión cuando observamos que la tasa anual de inflación está desmoronando las tradicionales instituciones sociales de nuestra comunidad? ¿Qué informaciones hay que producir y cómo hay que distribuirlas en el país para que impacten favorablemente como efecto multiplicador en los centros neurálgicos que generan el desarrollo nacional? ¿Cómo los espacios televisivos nos pueden ayudar a disminuir la creciente tensión provocada por la insatisfacción de los niveles mínimos de bienestar social? ¿Qué clase de programación hay que ofrecer a nuestra sociedad vía televisión cuando sabemos que después de 480 años de fundado el país, apenas en 1987 hemos alcanzado como promedio básico de conocimientos el sexto grado de primaria mental? ¿Qué tipo de insertos publicitarios deben existir en nuestro país, cuando sabemos que para 84 millones de habitantes que viven en la República Mexicana, sólo existe mil 800 bibliotecas públicas? ¿Qué tipo de cultura nacional debe formar la televisión cuando sabemos que es urgente aumentar en 7 millones de hectáreas la frontera agrícola del país para resolver las necesidades de alimentación de la población nacional en los próximos siete años $?^{16}$ ¿Qué clase de cultura hay que impulsar a través de la televisión cuando en una década, desde 1977 a 1987, la participación del trabajo en la

16 Urge aumentar en 7 millones de hectáreas las fronteras agrícolas del país, Excelsior, 4 de diciembre de 1987. 
formación del Producto Interno Bruto se ha reducido un 63.5\%, lo que significa que el trabajador del salario mínimo, por lo menos ha laborado gratis durante 5 años y medio ${ }^{17}$

¿Qué carácter deben tener las telenovelas cuando nuestra sociedad termina este sexenio de gobierno con más de 17 millones de desempleados y de ahora al año 2,000 se tendrán que crear, por lo menos, un millón de empleos anuales para satisfacer la demanda básica de la población?. ${ }^{18}$ ¿Qué clase de spots promocionales se deben difundir de hoy en adelante por las televisoras de Estado para gobernar civilizadamente al Distrito Federal, la ciudad más grande del mundo, que para finales de siglo tendrá 26 millones de habitantes y el Valle de

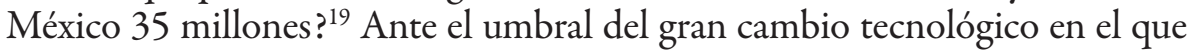
estamos ¿Qué cargas culturales hay que producir para que avance la reconversión industrial? ¿Qué concepciones debe difundir la televisión para incentivar un proyecto económico que permita producir para crecer internamente y no para pagar los simples intereses de la inalcanzable deuda externa de más de 112 mil millones de dólares?

Ahora bien, siendo que la televisión no puede propiciar de un sólo golpe la evolución de todos los cuadros mentales que existen en el país, sino sólo la transformación de algunos, esto exige la elaboración de una estrategia cultural muy precisa para determinar cuáles son aquellas áreas mentales vitales, cuyo avance se tiene que fomentar para generar un desenvolvimiento integral de la nación. Para evitar un derroche de esfuerzos en la producción de esta estrategia, que es una tarea sumamente amplia y compleja de realizar, debemos partir de una economía muy estricta de reflexión y acción.

La guía de este análisis debe estar conducido por la claridad que aporten las siguientes tres preguntas: 1) ¿Cuáles son las necesidades de desarrollo que hoy en día enfrenta la sociedad mexicana?; 2) ¿Cuáles son los actuales procesos sociales a través de los que se está originando el cambio fundamental de nuestro país?; y 3) ¿Cuáles son los mapas mentales que están impidiendo el avance del conjunto de la sociedad mexicana y cuya transformación puede provocar un efecto multiplicador que acelere el progreso de ésta?

Creemos que la conjunción de estas tres vetas del pensamiento y acción confluyen en la ejecución de una sola labor: la localización de los grandes problemas nacionales que actualmente impiden el progreso de nuestra sociedad.

17 Brusca caída de la participación del trabajo en el PIB, Excelsior, 15 de febrero de 1988.

18 Requiere el país crear anualmente un millón de empleos, Excelsior, 14 de febrero de 1988; Afecta ya el desempleo a 17 millones de mexicanos, Excelsior, 15 de febrero de 1988.

19 En el año 2000 la ciudad de México tendrá 26 millones de habitantes, Excelsior, 16 de febrero de 1988. 
Es por ello, que frente a esta situación debemos cuestionamos qué deben y qué pueden hacer las televisoras de Estado para propiciar la resolución de los principales conflictos estructurales de nuestro desarrollo.

Hasta el momento podemos decir, que en términos generales, la información que ha elaborado y diseminado la televisión nacional, básicamente ha surgido de los intereses espontáneos, de la presiones burocráticas, de los requerimientos coyunturales, de las "relaciones amistosas", de decisiones improvisadas, del "estado de ánimo" de los conductores, de propuestas experimentales, de la lógica del jefe, de las extremas presiones de tiempo que imponen la producción televisiva, de "intuiciones creativas", de oportunidades comerciales, de "compromisos contraídos", etc., pero no ha emanado el examen profundo y sistemático de las necesidades estructurales que enfrenta y requiere satisfacer el proyecto de crecimiento de la nación. De aquí, el gran abismo que se ha producido entre la cultura televisiva que han inculcado las instituciones audiovisuales y las deprimidas condiciones de vida que soporta la población mayoritaria de los municipios del país.

Curiosamente, la actividad publicitaria que es el área que más hemos combatido la generación de pensadores críticos sobre la comunicación en México, es el sector que con mayor profesionalismo ha aplicado la investigación para producir sus líneas informativas a través de la televisión: no produce ningún producto comunicativo sin análisis previos. El problema es que todas esas habilidades, recursos, conocimientos, experiencias acumuladas, etc., se dirigen hacia el único objetivo de cambiar o reforzar las mentalidades para la compra de un jabón, una cajetilla de cigarros, un refresco, un perfume, un automóvil, etc., y no para la modificación de nuestras actitudes ante los grandes problemas nacionales.

Para evitar caer nuevamente en esta gravísima desviación, es imprescindible, por una parte, que las televisoras estatales planifiquen orgánicamente la elaboración de su información audiovisual a partir del diagnóstico de las principales carencias que requiere resolver cada zona de desarrollo de la Nación. En otras palabras, a través de las televisoras y otros medios de comunicación se deben producir distintos paquetes emotivos e informativos envueltos en todos los géneros audiovisuales atractivos (telenovelas, mesas redondas, series informativas, programas, grabados, películas, series de concursos, videos espectaculares, etc.) cuyos contenidos generen una base de sensibilidad y conciencia que permita enfrentar las diversas urgencias que encara cada comarca de la República Mexicana. Esto significa, que hay que elaborar a través de la televisión nuevas políticas de programación, y por lo tanto, de educación formal e informal de los públicos, que partan de la localización de los conflictos que determinan la vida de los auditorios. 
Por otra parte, para abordar el progreso del país desde la televisión hay que generar con anticipación a la presencia de los conflictos, un cotidiano proceso educativo de evolución de las mentalidades y no esperar a que las contradicciones alcancen dimensiones críticas y desproporcionadas para que sean considera- das por las políticas informativas de las televisoras. Desafortunadamente, ésta ha sido la tónica de funcionamiento generalizado que ha seguido la televisión mexicana: la sensibilización de la población a través de la programación va enormemente rezagada de las inminentes necesidades de desarrollo que hay que solucionar, y éstas se encaran, sólo posteriormente cuando son realidades que adquieren proporciones alarmantes que ya son difíciles de controlar por los órganos de gobierno establecidos.

Por ejemplo, el caos ecológico no se abordó en sus orígenes a través de la televisión, sino que hasta que alcanzó la proporción de inversiones térmicas que redujeron la presencia del oxígeno para nuestras vidas. El problema del crecimiento demográfico no se enfrentó en sus principios, sino hasta que la concentración humana en manchas urbanas exigió la urgentísima planificación natal. La descentralización nacional no se planteó en los comienzos de la aglomeración social, sino hasta que la aguda falta de dotación de servicios y empleo en las ciudades exigió volver los ojos al interior del país. El desperdicio del agua no se abordó en su nacimiento, sino hasta que se agotaron los mantos acuíferos que nos dan la vida. La formación de una mínima cultura antisismos para el Valle de México, requerida desde hace décadas por ser muy vulnerable esta región ante los movimientos telúricos, se ha preparado raquíticamente sólo después de los devastadores terremotos del 19 y 20 de septiembre de 1985. La generación de una amplia cultura sexual que incluyese el empleo de preservativos y otros métodos preventivos para evitar el embarazo y el contagio de enfermedades venéreas, requerida urgentemente des- de principios de siglo, no se impulsó televisivamente a partir del surgimiento de este moderno medio de comunicación en los años cincuenta, sino hasta 1988 cuando apareció la moderna peste negra del siglo XX: el SIDA. El llamado a la solidaridad económica no se convocó ante los permanentes abusos de la clase gobernante, sino cuando la inflación llegó al 160\% anual de deterioro del poder adquisitivo.

De lo contrario, de no efectuarse esta urgente estratégica racionalización de flujo televisivo, se seguirán produciendo monumentales volúmenes cotidianos de información innecesaria que no se relaciona con las exigencias subjetivas que requieren adquirir los públicos para resolver sus contradicciones materiales y desvían y atomizan las conciencias, evitando el avance social de los mismos, con su consecuente retroceso humano. Así, por ejemplo, "la 
radiodifusión comercial continuará destinado más de sus dos terceras partes de información al entretenimiento, el 10\% a los programas educativos y orientadores y el $5 \%$ a tareas publicitarias. ${ }^{20}$

Ante esta realidad, nos preguntamos ¿Qué sentido tiene el que la televisión pública y privada inunde de 110 horas diarias, 770 horas semanales y 3 , 080 horas mensuales los hogares mexicanos? ¿Qué le deja a la maltrecha sociedad mexicana la importación de miles de contenidos visuales? ¿Qué le deja al pais la difusión masiva de tanta información desvinculada de nuestros principales problemas nacionales?

En la actualidad, nuestra República cuenta con la infraestructura de telecomunicaciones suficientes para provocar este avance de la sociedad mexicana. Por ejemplo, desde 1921 hasta la fecha la industria de la radiodifusión ha crecido a un ritmo de $7.7 \%$ anual que es una tasa superior a la de la expansión demográfica en este periodo. Incluso ha sido mayor a otras ramas de la comunicación más estratégicas para el desarrollo económico del país como son los ferrocarriles que en 77 años, es decir, desde la época pos revolucionaria de 1920 a la fecha sólo ha crecido un $25 \%$ con un tendido de 5 mil kilómetros de vías férreas. ${ }^{21}$

Esta expansión vertiginosa de las telecomunicaciones ha generado en 60 años en el terreno material, una gigantesca capacidad instalada de 16 mil cien kilómetros de microondas con 224 estaciones repetidoras y 110 terminales; dos satélites de difusión doméstica, el Morelos I y II con 205 estaciones terrenas para televisión y radio (de las cuales 13 son estaciones transreceptoras) y 27 más en proceso de instalación; 875 estaciones de radio de las cuales 665 son de Amplitud Modulada (25 son culturales) y 200 de Frecuencia Modulada (11 culturales); 192 estaciones de televisión de las cuales 78 funcionan en convenios con empresas privadas y 111 son operadas por los gobiernos de los estados o patronatos locales; 4 canales de cobertura nacional (2, 5, 7 Y 13); 72 sistemas de televisión por cable, más de 16 mil videoclubes, 40 empresas dedicadas a la producción del video, y más de $3 \mathrm{mil}$ 500 salas cinematográficas con la presentación de aproximadamente mil 500 funciones diarias en el país. ${ }^{22}$

20 Jiménez Espriu, Javier Panorámica y perspectivas de la radiodifusión en México, Secretaría de Comunicaciones y Desarrollo Tecnológico (SCT), Primer Encuentro Latinoamericano y del Caribe de Radio y Televisión, México 1986, Guadalajara, Jalisco, 30 de octubre de 1986, páginas 4 y 5.

21 De 1910 a la fecha la red de trenes sólo creció 5 mil kilómetros, Excelsior, 10 de febrero de 1987.

22 Los medios de difusión masiva tienen un papel central en la renovación, Excelsior, 16 de noviembre de 1986 
En el campo de la formación de recursos humanos en comunicación, contamos con más de 60 escuelas de información, 15 mil docentes especializados en esta área, 30 mil alumnos y más de 100 mil profesionales formados de esta rama en toda la República.

Es por ello que, a principios de siglo, por la incipiente expansión de las comunicaciones masivas no podíamos adquirir rápidos y nuevos estados de con- ciencia colectivos que nos permitieran evolucionar aceleradamente por los rumbos que exigía el cambio global de la sociedad pre revolucionaria. Fueron los procesos de comunicación lentos y aislados los que, poco a poco, en la medida en que entraron en contacto unos con otros y se fecundaron entre sí, los que gesta- ron la visión de un cambio profundo de la sociedad mexicana que dio origen a la Revolución de 1910.

Sin embargo, al contrario, ahora en 1988 contamos con un avanzadísimo sistema de telecomunicaciones electrónicas que pueden provocar una sistemática sensibilización a domicilio de las conciencias para crear las mutaciones necesarias que requiere producir el urgente proyecto de sobrevivencia de la sociedad mexicana.

Por lo mismo, estamos convencidos que las condiciones tecnológicas y de formación de recursos huma-nos para el cambio espiritual del país ya están dadas. Lo que queda ahora es efectuar el trabajo politico para lograr la reorientación del contenido de tales avances electrónicos para impulsar el urgente salto mental que requiere nuestra sociedad.

Creemos que de nada servirá el enorme esfuerzo administrativo, político, de innovación tecnológica, de capacitación de cuadros humanos creativos, de organización, de movilización, etc., que exige el nuevo proyecto de televisión pública, si toda esta infraestructura no es enfocada al cambio de nuestra mentalidad sobre los grandes problemas nacionales. Si la televisión no sirve para esto, nos preguntamos ¿Qué sentido puede tener su presencia en el país? Si la televisión sólo colabora a entretener, divertir, informar pero no contribuye a la transformación humana de la población ¿Qué la puede justificar? Si la televisión no crea mayores niveles de conciencia colectiva sobre las trabas que impiden nuestro desarrollo, ¿Cómo defender la ampliación tecnológica que durante más de 50 años ha logrado el Estado Mexicano a través del tejido televisivo para llegar a la recámara, la sala y la cocina de todos los hogares mexicanos? Si no es útil para estos fines ¿Por qué no dar paso entonces a otras relaciones de comunicación más vitales como son el encuentro familiar y los vínculos personales que tanto ha desplazado la presencia de la televisión?

Pensamos que en este periodo de transformación acelerada por el que atraviesa nuestra sociedad, el único sentido que fundamenta la existencia de 
la televisión, es el aprovechar al máximo su gran potencial pedagógico para producir mayores niveles de conciencia colectiva sobre nuestras problemáticas, que nos sirvan para organizar a los municipios y delegaciones del país de forma que permitan recobrar los hilos del proyecto nacional perdidos y aminoren la crisis global que nos des integra como Nación. Por lo anterior, creemos que la razón de ser de la televisión mexicana y si alguna justificación tiene la presencia del Estado en ésta, es la de colaborar a través de ella a conocer y sentir más nuestro país para adquirir mayores niveles de claridad que nos permitan hacerlo progresar y no desmovilizar y dispersar a la sociedad a través de la permanente diversión espectacular y el entretenimiento fugaz.

Por lo mismo, estimamos que de seguir utilizando mayoritariamente la televisión para el esparcimiento es casi como aceptar que las principales carreteras del pais, que también son vias de comunicación estratégicas, sólo se aprovechen para transitar a los centros vacacionales, los cabaretes, los clubes de golfo, las canchas de tenis, etc., y por lo tanto, los transportes de carga, los automotores de trabajadores, los vehiculos oficiales, los automóviles de negocios, los camiones de la industria de la construcción, etc. no deben circular por éstas.

Tenemos que entender que el monumental esfuerzo material que ha hecho la sociedad mexicana durante más de 50 años para desarrollar el sistema nervioso televisivo del país, no ha sido para destinar este estratégico recurso cultural para la simple promoción publicitaria o el esparcimiento nocturno, sino para enfocar estas herramientas para la educación y transformación mentales del país frente a sus grandes conflictos de crecimiento, uno de los cuales, en un porcentaje mínimo, es el entretenimiento.

Por lo anterior, consideramos que con la misma cantidad de técnicas, los mismos estudios, la misma iluminación, los mismos desayunos, el mismo presupuesto, los mismos memorándums, la misma saliva, las mismas calorías, etc., que se dedican, hoy día, para producir la actual televisión mayoritariamente parasitaria, se puede generar una nueva programación que propicie el desarrollo del país: la información de con- tenido social genera la superación de nuestra sociedad y la comunicación de fuga de la realidad produce el retraso de nuestra Nación. En el presente, lo que le falta al Estado Mexicano para lograr a través de la televisión este avance mental de la sociedad frente a su crisis de desarrollo son dos cuestiones: por una parte, la elaboración de una nueva concepción de la función orgánica que deben ejercer los aparatos audiovisuales frente a las exigencias del crecimiento social. Y por otra, la presencia de una nueva voluntad politica para lograrlo.

En la actualidad, pensamos que en el terreno informativo hemos avanzado mucho en la innovación de nuevas tecnologías de comunicación, en la for- 
ma especializada de cómo transmitir los datos, en la manera de cómo abordar casi exhaustivamente la vista y el oído a través de imágenes y sonidos, en la capacitación de cuadros altamente profesionales, etc.; pero el gran problema es que todavía no sabemos cómo utilizar los canales de difusión para contribuir a resolver los grandes conflictos que encaramos en cada fase de nuestra evolución histórica. Por ello, creemos que el proyecto de modernización de la televisión de Estado, enorme-mente solicitado por los sectores mayoritarios y representativos de la sociedad mexicana, no provendrá de la adquisición de nuevas computadoras visuales para descomponer el color, de la incorporación del sonido estereofónico a la señal auditiva, del aumento de la cobertura televisiva, del enlace instantáneo de la señal a todos los rincones de los municipios, de la introducción de nuevos lenguajes visuales en la pantalla, de la modificación del logotipo de la imagen, etc., sino en la medida en que la televisión de Estado aborde el cambio de nuestras culturas cotidianas frente a los grandes problemas del pais.

Por lo mismo, insistimos que considerando que la televisión es la principal red educativa que existe en nuestra sociedad, la pregunta central sobre ésta no es cómo renovarla a través de la incorporación de nuevas tecnologías sino el indagar cómo aprovecharla para la transformación mental de nuestra sociedad ante sus principales obstáculos que le impiden crecer. La modernización del país no se logrará si no se construye a través de la televisión una nueva cultura ante nuestros dilemas de crecimiento.

Si los medios de comunicación y en especial de la televisión no optan por la superación de los conflictos del país, nos cuestionamos ¿Por qué la sociedad mexicana deberá seguir pagando el funcionamiento parasitario de éstos? La sociedad civil necesita despertar de la oscuridad mental en la que hemos permanecido muchas décadas y que nos ha impedido tomar conciencia de que, bajo cualquiera de las dos formas de financiamiento tradicional de los medios, el mercantil o el subsidio público, finalmente, su funcionamiento lo pagamos los receptores. Por el publicitario, porque el monto que se invierte en este rubro es cargado por la empresas como costo de producción al precio último de los productos que pagamos los consumidores. Por el subsidio gubernamental, porque proviene del erario público que se forma de los impuestos que aportamos los ciudadanos. Por lo tanto, la operación de los medios de comunicación en el país, bajo una u otra modalidad, siempre la pagamos los espectadores. Por ello, la televisión tiene la obligación irrenunciable de atender las necesidades de elevación del nivel de vida de sus auditorios. 


\section{DOCUMENTACION CONSULTADA.}

Afecta ya el desempleo a 17 millones de mexicanos, Excelsior, 15 de febrero de 1988. Al maratón de Guadalajara 4, 000 corredores, Excelsior, 4 de febrero de 1987. Aplicarán hoya 12 millones de infantes la vacuna antipolio, Excelsior, 24 de enero de 1987.

Aplicó la armada 75 mil dosis de vacuna antipolio, Excelsior, 29 de enero de 1987. Bajaron los accidentes laborales en 57\%: IMSS, Excelsior, 10 de febrero de 1987. Bernal Sahagún, Víctor M., Programa Intersticios, tema: La publicidad, Radio Educación, 18 de julio de 1988.

Brusca caida de la participación del trabajo en el PIB, Excelsior, 15 de febrero de 1988.

Cada vez más consumidores hacen valer sus derechos: Pliego Montes, Excelsior, 11 de febrero de 1987.

De 1910 a la fech a la red de trenes sólo creció 5 mil kilómetros, Excelsior, 10 de febrero de 1987.

Del 26 al 30, vacunas contra el sarampión: SSA, Uno más Uno, 20 de octubre de 1987.

Descendió el analfabetismo a 7.6\%, Uno Más Uno, 27 de marzo de 1987.

El paseo ciclista, un freno a la contaminación, Excelsior, 5 de junio de 1987.

El próximo sábado la segunda jornada de vacunación antipolio, Excelsior, 22 de marzo de 1986.

En el año 2000 la ciudad de México tendrá 26 millones de habitantes, Excelsior, 16 de febrero de 1988.

Está preparando al FSTSE a 45 O, 000 promotores del voto, Excelsior, 2 de julio de 1987.

Esteinou Madrid, Javier, El estudio materialista de la comunicación de masas, Cuadernos del TICOM No. 1, Taller de Investigación para la Comunicación Masiva, Departamento de Educación y Comunicación, Universidad Autónoma Metropolitana, Unidad Xochimilco, mano de 1979.

Esteinou Madrid, Javier, El sistema Morelos de satélites y su impacto en la sociedad mexicana, V Encuentro Latinoamericano de Facultades de Comunicación Social, Bogotá, Colombia, 6 al 10 de octubre de .1986.

Esteinou Madrid, Javier, La reconstrucción y los medios de comunicación, El Búho, No. 15, suplemento cultural de Excelsior, 22 de diciembre de 1985. Esteinou Madrid, Javier, Los medios de comunicación y la construcción de la hegemonía, Editorial Nueva Imagen Centro de Estudios Económicos, Políticos y Sociales del Tercer Mundo (CEESTEM), México, D.F., 1983.

Esteinou Madrid, Javier, Televisión y memoria social (dos partes), El Búho, 
Nos. 35 y 36, Excelsior, 11 y 18 de mayo de 1986.

Fracasó la televisión, no todo es vender detergentes, Excelsior, 5 de agosto de 1988.

Hoy 92 de cada 100 adultos mexicanos saben leer y escribir, Excelsior, 13 de diciembre de 1986.

Jiménez Espriu; Javier Panorámica y perspectivas de la radiodifusión en México, Secretaría de Comunicaciones y Desarrollo Tecnológico (SCT), Primer Encuentro Latinoamericano y del Caribe de Radio y Televisión, México 1986, Guadalajara, Jalisco, 30 de octubre de 1986, páginas 4 y 5. Las campañas de vacunación han logrado reducir $35 \%$ las enfermedades infantiles, Excelsior, 12 de marzo de 1986.

Los medios de difusión masiva tienen un papel central en la renovación, Excelsior, 16 de noviembre de 1986.

Millón y medio de niños serán vacunados contra la polio en el D.F., Excelsior, 21 de enero de 1987.

Preparación básica de la formación de recursos humanos en comunicación para el desarrollo, Segunda Reunión de Consulta, UNESCO UIA, 1820 de mayo de 1987, México D.F. p. 1, Coordinador general del proyecto Mtro. Pablo Casares A.

Reconocimiento de la UNESCO al gobierno mexicano por los resultados de programas de alfabetización, Uno Más Uno, 9 de septiembre de 1987.

Reconoció MMH el apoyo publicitario a las campañas del sector público, Excelsior, 29 de septiembre de 1987.

Requiere el pais crear anualmente un millón de empleos, Excelsior, $14 \mathrm{de}$ febrero de 1988.

Respuesta al festival del donador altruista de sangre, Excelsior, 14 de octubre de 1987.

Se inmunizó contra la polio a 12 millones de infantes, Excelsior, 25 de enero de 1987.

Serán inmunizados contra la polio más de doce millones de niños, Excelsior, 14 de enero de 1987.

Toussaint, Florance, La televisión y los resultados electorales, Proceso, 25 de julio de 1988.

Urge aumentar en 7 millones de hectáreas las fronteras agricolas del pais, Excelsior, 4 de diciembre de 1987.

Vacunados más de 10 millones de niños contra difteria y tosferina, Excelsior, 23 de mayo de 1987.

15,000 atletas en la carrera de la Constitución, Excelsior, 8 de febrero de 1987. 